\title{
Children from Immigrant Families - Adaption, Development, and Resilience. Current Trends in the Study of Migration in Europe
}

\author{
Birgit Leyendecker
}

\section{Integration is the Preferred Strategy}

Much of our knowledge on immigration and adaptation processes is based on studies of migration from the "old world" to the "new world". According to Berry (2003), research revealed that neither assimilation nor separation nor marginalization but integration is the strategy preferred by most immigrants. Berry describes the integration strategy as maintaining interest in daily interactions with members of the own ethno-cultural group while at the same time seeking participation within the larger society. Over the course of two or three generations, immigrants are likely to become an integral part of the U.S., Canada, or Australia, either undistinguishable from the majority society or as part of the minority society (Portes \& Rumbaut, 2001). One exception to this pattern is the increasing number of transnational immigrants. They are comprised of individuals or families who move back and forth across borders, often for business reasons without establishing a permanent residence (Fuligni, 2010). For most others, the familiar hyphenated identity indicates only the ethnic background (e.g., African-American, ItalianAmerican, Native-American) while the main emphasis is on being American.

However, there are some strong indicators that acculturation processes of inter-European migration today manifest a slightly different pattern when compared to migration from Europe in the past centuries. Rather than becoming an integral part of the host society and valuing their newly acquired citizenship, inter- European migrants may choose to become an integral part of both host and origin societies. These immigrants and their offspring have the option of staying connected not only with the ethno-cultural group in the receiving country but also with the country of origin, including the former's political and societal institutions. Close proximity between the country of emigration and the country of immigration, inexpensive flights, lengthy vacations of at least one month per year as well as modern media facilitate the contact to the country of origin. One indicator for this trend towards a new and possibly unique European cultural identity of immigrants is the preference of migrants to acquire and to maintain dual citizenships. This new type of hybrid identity could be seen as a problem, for instance as not being at home in either country, being a stranger in both countries, or as "sitting between two chairs" (as formulated in the German language). However, this is not the case, and it appears to be a possible pathway preferred by many new European immigrants.

\section{Diversity Versus Unequal Diversity}

From a psychological point of view, a positive attitude of immigrants towards both countries is considered to be of vital importance for a successful adaption. This 
positive attitude is expressed on a much deeper level than superficial preferences for music, food, or specific festivities. Suarez-Orozco and Suarez-Orozco (2001) point out the important role parents play for the process of finding a balance between the values of the home culture and the appreciation for the societal culture. Their research suggests that children have the highest chances of fully taking advantage of the available opportunities in their country of residence if they develop strong bicultural and bilingual competencies. This means that children and their parents are confronted with the task to seek a sense of balance and to become firmly rooted in their family and culture of origin as well as in their country of residence (Stuart, Ward, \& Adam, 2010).

If the integration of two cultures is best for children and if integration is a strategy preferred by most immigrants - then why is there so much talk about the problems associated with immigration and integration? Could this be explained by the (perceived) slowness of individuals in adapting or a public opinion informed by politicians who are prone to demand integration but who often confuse integration with assimilation? Or are European societies still at heart national societies who have difficulties in accepting diversity and tolerating the immigrants' strong connection to their country of origin? Maybe the problem associated with immigration is not diversity per se but rather unequal diversity, as Portes and Vickstrom (2011) conclude in their literature review. They point out that unequal ethnic diversity is often perceived as problematic and may hinder social cohesion and social capital. In Europe, immigrants are from all socio-economic strata and include highly skilled as well as unskilled workers. However, the term immigrant is more and more associated with low socioeconomic status (SES) and unskilled workers, therefore carrying an implicit reference to socioeconomic disparity. In Germany, for example, the city of Düsseldorf is very proud of hosting the second largest Japanese population in Europe. Japanese stores and restaurants, buildings of Japanese corporations in the expensive downtown area of the 'Immermannstrasse' as well as the yearly festival called Japan Day attract many tourists and locals alike, and contribute to the international flair of the city. However, the Japanese population consists of less than 9,000 people and is clearly outnumbered by immigrants from Turkey, Greece, and the former Soviet Union (http://www.duesseldorf.de/statistik). Yet in contrast to many other immigrant groups, the Japanese population in Düsseldorf is homogeneously well educated and financially well off. They have their own schools, golf clubs, culture centers and Buddhist temples. The Japanese population is obviously perceived as an asset and not as a threat or a problem. This is illustrated by the fact that they are referred to as the 'Japanese community' rather than 'the Japanese immigrants' as is done in the case of 'Turkish immigrants'. In Europe, this exemplifies a divide between low-status immigrants, such as people with roots in Turkey or Morocco, and high-status immigrants from Japan or Scandinavia. This pattern of a positive and negative bias towards immigrants has been described for countries outside of Europe as well (Alba, Sloan, \& Sperling, 2011).

\section{Different Flows of Migration}

In all countries of the European Union (EU), part of the population is made up of immigrants from other EU countries. With few exceptions, they do not represent sizable numbers from one single country, but are from a wide range of EU countries. These European migrants do not need a working permit and usually do not attempt to acquire a new passport, as this provides little advantages aside from being able to vote in national elections. They may come for shorter or longer periods of time and manifest a high degree of diversity in terms of education and the reason for their migration. However, they all have the following characteristics in common: their presence is usually not perceived as a problem, they are accepted by the host society, and they can move back and forth as much as they want to. These immigrants appear in the national statistics, but are largely ignored both by national politics as well as by scientific research. Only some brief periods of concern should be noted here, e.g., after Poland joined the EU and countries like Germany were afraid of massive labor migration.

In terms of the positive and negative bias towards immigrants described above, migration to Europe is forked into three great flows of migration. First, there is the relatively small group of those manifesting a high human and financial capital such as the Japanese community, IT workers, researchers, and other coveted highly skilled professionals who are in strong demand in almost every country. Starting in 2011, the European Union is trying to attract them with the so-called 'Blue Card'.

Second, there is the much larger group of individuals who came as labor migrants and as diaspora migrants. Around the wake of the economic boom of the late 1950 s and 1960 s, many Northern European countries 
recruited migrants for manual labor. While many of these so-called guest workers eventually returned, others decided to stay. The size of this group was later increased through family reunion. In addition, all European countries host a large group of refugees and asylum seekers, and some are the home of diaspora migrants. The term diaspora migrants refers to those who have lived outside of their country of origin for generations, often for many centuries, who have remained a distinctive minority and who now have decided to return to their ancestral home countries (Silbereisen, 2008). Examples of this typology would be people of Jewish or of German origin in Eastern Europe, or the ethnic Greeks in Albania. The third flow is the underground migration of extralegal undocumented immigrants who can rely neither on the legal system for the protection of their rights nor on the health care system for medical treatment (Portes, Fernandez-Kelly, \& Light, 2010). This group is in widespread demand for labor, e.g., during the harvest season and in construction, yet otherwise invisible and completely unprotected.

This special issue of the International Journal on Developmental Science focuses on the second group that has received the most attention in research the offspring of labor migrants and/or the more recent immigrants from Eastern and South-Eastern Europe (Jäkel, Schölmerich, Kassis, \& Leyendecker, 2011; Moscardino, Bertelli, Altoè, 2011; Stefanek, Strohmeier, van de Schoot, \& Spiel, 2011; Stoessel, Titzmann, \& Silbereisen, 2011) children of refugees and asylum seekers (Oppedal, 2011), and children of diaspora migrants (Motti-Stefanidi, Pavlopoulos, \& Tantaros, 2011; Stoessel et al., 2011). In each country represented in this volume, children from immigrant families form an increasingly large number of the general populations. For centuries, Norway, Austria, Germany, Greece, and Italy represented the classical countries of emigration. As different as these countries are, they all have in common that they have only recently realized and accepted that they have become preferred countries of immigration.

\section{Differences Between Migration to North America and Europe}

Aside from the preference of staying closely connected to the country of origin, there are some other features distinctive to the European context of immigration. In the US and Canada, many children have parents who were already born in the host country. These children are the third generation or, if their grandparents were already born in the US or Canada, they are even fourth generation and usually referred to as a minority and no longer as immigrants. The stressful and uprooting experiences of the migration process itself - such as leaving behind family and friends, experiencing language deficiencies, a devaluation of skills and competencies, adapting to an unknown environment and unfamiliar social customs, adjusting to an unfamiliar school system - are not applicable to third or fourth generation children.

In contrast to North-American studies on immigration, most immigrant children in Europe are second generation migrants and less likely to be third or even fourth generation migrants. Here, we can roughly differentiate between two groups. First, many children are likely to be either the offspring of the immigrants who moved in large numbers from Eastern Europe to countries of the European Union or other Western European countries such as Switzerland and Norway. Second, many children have parents of a mixed generational status consisting of one first and one second generation immigrant. Marriages between a first and a second generation partner are likely to occur when one or all of the following constraints apply: (a) family reunion is the major legal way of entry for new immigrants, (b) immigrant parents prefer their children to marry someone from the country of origin, (c) the home country is easily accessible, and families tend to spend the vacation time in their country of origin, and (d) those women who have acquired a higher education have a better chance of finding a well- educated husband in their country of origin (Leyendecker, Schölmerich, \& Citlak, 2006). These marriages between first and second generation immigrant partners can be found in many European countries. As a result, the majority of children from immigrant families have at least one parent who grew up in the country of origin. This keeps culture and language of the country of origin alive in these families. Therefore, children of these parents are more likely to resemble second than third generation children.

\section{Contribution of Societies and Families to Meet the Challenges of Disparity}

Given this specific migrational pattern, the enormous demographic shifts in European societies are most visible amongst children. While immigrants are underrepresented among retirees they are very much present among pre-school and school age children. Almost all 
European countries now face the challenges of integrating children from diverse ethnic backgrounds and facilitating their access to a good and comprehensive education. Studies on parents' involvement as well as on the role of schools and on the climate in classrooms are critical in understanding how societies can meet this challenge and ameliorate the disparity between children of immigrant origin and native children.

The psychosocial adaptation of children from immigrant families as well as children's academic achievements are important indicators of their social integration. How can families, schools, societal and political institutions contribute to children's well-being, maximize their learning opportunities and their chances of participation in the society at large? On a macrolevel, social and political forces, particularly the characteristics of the educational system and the role of early school tracking in countries such as Germany, Austria, and the German-speaking part of Switzerland are likely to play a role (Maaz, Trautwein, Lüdtke, \& Baumert, 2008). Children of poorly educated immigrant parents were often found to lag behind children of well- educated native middle class families. The reasons for this disparity are likely to differ between countries and their educational system, as recent research on the academic success of the second generation of Turkish immigrants in Europe suggests. The TIES study found a large variation across European countries for young adults of the Turkish second generation. Among young Turkish adults, Germany has a high percentage of early school drop-outs and a low percentage of people who acquire a university education when compared to countries such as France, The Netherlands, Switzerland, Belgium, and France (Wilmes, Schneider, \& Crul, 2011).

The papers in this special issue contribute to our understanding of immigration processes by analyses performed on a micro-level, on a meso-level or on both. The micro-level studies examine the role of the family on children's development - how do key characteristics of parents such as their parenting cognitions, ethnic identity and acculturation influence children's everyday experiences within the family context? Several papers look more closely at the processes within the child's family. Moscardino et al. (2011) observed and compared mother-infant interaction among recent immigrants from Romania in Italy with non-migrant mother-infant pairs residing in Italy as well as in Romania. For the immigrant sample, they found that the Romanian mothers placed more emphasis on values related to interdependence when compared to the Italian mothers. In many aspects, the parenting beliefs of the
Romanian immigrant mothers resembled more closely the beliefs of the Italian mothers than the beliefs of the Romanian non-migrant mothers. Interestingly, the observation of mother-child interaction and the parenting beliefs were not related. Such observational studies on parent-child interactions are very rare. Compared to interview and questionnaire studies, they pose more challenges on several levels, such as the recruitment of individuals who agree to be videotaped and the time consuming process of data coding. However, as the paper by Moscardino et al. (2011) demonstrates again, researchers have to be very careful when interpreting beliefs and attitudes as they may not be closely associated with actual behavior and are therefore not the best indicator for children's day-to-day experiences.

The findings of the TIES study described above (Wilmes et al., 2011) point to the specific importance of the home environment and parents' education for immigrant children in Germany. This is because the education system does not appear to be well suited to provide the much needed additional support. The importance of parental education for explaining children's cognitive and academic development has been found for children from immigrant and non-migrant families alike (Baumert, Stanat, \& Watermann, 2006). The paper by Jäkel et al. (2011) examines the influence of the home literacy environment of pre-school children of Turkish immigrant families and non-migrant families in Germany. Within the micro level of the family, both immigrant and non-migrant children who grow up with parents who provide a stimulating literacy environment are likely to receive higher scores on cognitive tests and on language proficiency. The findings by Stoessel et al. (2011), who studied the transition of Turkish and Russian immigrant children and German native children into pre-school and into first grade in Germany support this notion. They found maternal education to be a critical factor in explaining differences between these three groups. The additional stimulation received in pre-school and school was not able to diminish the influence of maternal education.

\section{Adaptation and Resilience}

On the meso-level, quantitative aspects such as resources and ethnic composition of a classroom, qualitative aspects such as social support provided by teachers, quality of the teacher-child relationship, conflict and closeness, as well as peer-conflicts influence how children adapt. How do children and adolescents 
in spite of sometimes adverse conditions forge their senses of identity and find their pathways through interactions with families, peers, schools, and communities? Motti-Stefanidi et al. (2011) investigated the relationship between Albanian immigrant adolescents and their parents as well as their class-mates in Greece. They found that these adolescents did not differ in terms of the amount of conflict with parents when compared to native Greek students of the same age group. The Albanian immigrant group studied by Motti-Stefanidi et al. (2011) has several unique features that sets them apart from other groups, for example from people of Turkish origin. In contrast to most other immigrant populations this group appears to prefer to assimilate at least as far as external features are concerned. Even though not all are actually diaspora migrants, they are likely to make a big effort to blend in by strategies such as declaring themselves to be of Greek ethnic origin, by changing their names to Greek names, and by baptizing their children or themselves in the Greek Orthodox Church. In addition, this group shows some remarkable characteristics pointing to resilience. Even though they were academically less successful, more likely to experience discrimination and more likely to live in greater social adversity when compared to native Greek adolescents, they were not found to differ in terms of psychological well-being. This is particularly remarkable in light of the assimilation strategy. This strategy is unexpected and rare (Berry, 2003) and not considered to support children's psychological well-being (Suarez-Orozoco $\&$ Suarez-Orozco, 2001).

Similarly, Stefanek et al. (2011) found that adolescents with origins in Turkey or in the former Yugoslavian Republic were less likely to be victims of bullying when compared to adolescents from Austrian families. For future research, the findings of studies by Stefanek et al. (2011) as well as by Motti-Stefanidi et al. (2011) point to the importance to focus not only on risk factors but also on protective factors promoting resilience. While associations between assimilation and resilience have not been found in other studies, social support by the family, peers, and in the community is considered to be one of the key protective factors (Masten \& Obradovic, 2006). The findings of the research by Oppedal (2011) on the mental health of Turkish, Somali, Tamil, and Vietnamese pre-adolescents and adolescents in Norway demonstrate the importance of social support. She found that social support can counterbalance the negative impact of ethnic discrimination. Especially the adolescents from Somalia, who were less established and more visible when compared to
Turkish, Vietnamese, and Tamil youth, benefited from social support by their class mates and their families.

\section{The Importance of a Developmental Perspective}

Understanding causes and consequences of individual and group differences with respect to health outcomes, social integration, and academic achievement are critical to supporting immigrant families and to designing educational environments that promote children's and adolescents' well-being and maximize their learning opportunities and chances of participation in the society at large. Research on immigration in Europe is still scarce but necessary in order to understand the specific characteristics of the European context and in order to provide a basis for the allocation of resources. In recent years, more and more studies have attempted a longitudinal perspective necessary to trace the development of children from immigrant families.

Sam, Kosic and Oppedal (2003) point to the difficulties of differentiating between normal developmental processes of children and adolescents on the one hand, and problems associated with immigration and acculturation on the other hand. Two studies in this special issue (Motti-Stefanidi et al., 2011; Stoessel et al., 2011) try to untangle the changes that occur over time for children and youth from immigrant families. They approach this subject from quite different perspectives. The study by Motti-Stefanidi et al. (2011) provides an insightful example of the danger of 'pathologizing' children from immigrant families. At the first point of their assessment, the children from Albanian immigrant families reported higher levels of conflict with their parents when compared to children from non-migrant Greek families. However, in both groups frequency of conflict decreased over time, more pronounced in the former than in the latter group. As a result, these differences were not evident anymore at the time of the second assessment.

While children of immigrants clearly do have to deal with more challenges than non-migrant children, their development may also be accelerated by the experiences of being exposed to two cultures and to two languages simultaneously. For example, recent studies on the cognitive development of children point to the advantages of bilingualism (Carlson \& Meltzoff, 2008; Rivera Mindt et al., 2008; see Bialystok, 2009 for an overview). Along this line, the study by Stoessel et al. (2011) points to the developmental gains of children from immigrant families after the transition 
to kindergarten and to elementary school. All children improved on measures such as language development and self-control. These gains, however, were more evident for the children of Turkish immigrant families than for the children of non-migrant German families. Mastering a new language as well as getting oriented in a new socio-cultural environment with unfamiliar rules and behavioral expectations appeared to be a positive challenge to these children and to be particularly beneficial.

Understanding the cascade effects of achievements and failures over time in childhood and adolescents will have important implications for the study of resilience (Masten \& O'Dougherty Wright, 2010). Cooper (2011) suggests that in order to understand how children and adolescents from immigrant families find their pathways and succeed despite adverse conditions, one needs to trace the interplay of challenges and support on the personal, relational, institutional, and cultural level. Taking this approach seriously, we need to conduct more research that combines (1) a developmental perspective in order to examine the slope of growth curves on important indicators of children's well-being, (2) a perspective of features promoting resilience to elucidate the contribution of families, schools, peers, and communities, and (3) an ecological perspective in order to understand how multiple levels directly and indirectly interact and influence how children from immigrant families negotiate these developmental and cultural transitions.

\section{References}

Alba, R.D., Sloan, J.D., \& Sperling, J. (2011). The integration imperative: The children of low-status immigrants in the schools of wealthy societies. Annual Review of Sociology, 37, Doi: 10.1146/annurev-soc-081309-150219.

Baumert, J., Stanat P., \& Watermann, P., Eds., (2006). Herkunftsbedingte Disparitäten im Bildungswesgen. VS Verlag für Sozialwissenschaften, Wiesbaden.

Berry, J. (2003). Conceptual approaches to acculturation. In K.M. Chun, P. Balls Organista, \& G. Marin Eds., Acculturation. Advances in Theory, Measurement, and applied research (pp. 18-37). American Psychological Association, Washington, DC.

Bialystok, E. (2009). Bilingualism: The good, the bad, and the indifferent. Bilingualism, Language, and Cognition, 12, 3-11.

Carlson, S.M., \& Meltzoff, A.N. (2008). Bilingual experiences and executive functioning in young children. Developmental Science, 11, 282-298.

Cooper, C. (2011). Bridging multiple worlds. Culture, identities, and pathways to college. Oxford University Press, Oxford.
Fuligni, A. (2010). Commentary: The benefits and challenges of belonging. ISSBD Bulletin, 58, 19-22.

Jäkel, J., Schölmerich, A., Kassis, W., \& Leyendecker, B. (2011). Mothers and fathers bookreading predicts preschoolers development in Turkish immigrant and German families. International Journal of Developmental Science, 5, 27-39.

Leyendecker, B., Schölmerich, A., \& Citlak, B. (2006). Similarities and differences between first- and second generation Turkish migrant mothers in Germany: The acculturation gap. In M.H. Bornstein, \& L. Cote Eds., Acculturation and parent-child relationships: Measurement and development, (pp. 297-315). Erlbaum, Mahwah, NJ.

Maaz, K., Trautwein, U., Lüdtke, O., \& Baumert, J. (2008). Educational transitions and differential learning environments: How explicit between-school tracking contributes to social inequality in educational outcomes. Child Development Perspectives, 2, 99-106.

Masten, A., \& Obradovic, J. (2006). Competence and resilience in development. Annals of the New York Academy of Science, 1094, 13-27.

Masten, A., \& O’Dougherty Wright, M. (2010). Resilience over the lifespan. Developmental perspectives on resistance, recovery, and transformation. In J.W. Reich, A.J. Zautra, \& J.S. Hall Eds., Handbook of adult resilience (pp. 213-237). Guilford Press, New York.

Moscardino, U., Bertelli, C., \& Altoè, G. (2011). Culture, migration, and parenting: A comparative study of mother-infant interaction and childrearing patterns among Romanian, Romanian immigrant and Italian families. International Journal of Developmental Science, 5, 11-25.

Motti-Stefanidi, F., Pavlopoulos, V., \& Tantaros, S. (2011). Parentadolescent conflict and adolescents' adaptation: A longitudinal study of Albanian immigrant youth living in Greece. International Journal of Developmental Science, 5, 57-71.

Oppedal, B. (2011). The role of social support in the association between perceived discrimination and mental health among young immigrants in Norway. International Journal of Developmental Science, 5, 85-99.

Portes, A., \& Vickstrom, E. (2011). Diversity, social capital, and social cohesion. Annual Review of Sociology, 37. Doi: 10.1146/annurev-soc-081309-150022.

Portes, A. \& Rumbaut, R. Eds., (2001). Legacies: The story of the immigrant second generation, University of California Press, Berkeley.

Portes, A., Fernandez-Kelly, P., \& Light, D.W. (2010). Life on the Edge: Immigrants confront the American Health System. Center for Migration and Devleopment, Working Paper 10-05. http://cmd.princeton.edu/papers/wp1005.pdf, retrieved April 13, 2011.

Rivera-Mindt, M., Arenthoft, A., Germano, K.K., DAquila, E., Scheiner, D., Pizzirusso, M., Sandoval, T.C., \& Gollan, T. (2008). Neuropsychologtical, cognitive, and theoretical considerations for evaluation of bilingual individuals. Neuropsychological Review, 18, 255-268.

Sam, D.L., Kosic, A., \& Oppedal, B. (2003). Where is "development" in acculturation theories? ISSBD Bulletin, 44, 4-7.

Silbereisen, R. (2008). New research on acculturation among diaspora migrants. International Journal of Psychology, 43, 2-5.

Stefanek, E., Strohmeier, D., van de Schoot, R., \& Spiel, C. (2011). Bullying and victimization in ethnically diverse schools: Risk and 
protective factors on the individual and class level. International Journal of Developmental Science, 5, 73-84.

Stoessel, K, Titzmann, P., \& Silbereisen, R.K. (2011). Children's psychosocial development following the transition to kindergarten and school: A comparison between natives and immigrants in Germany. International Journal of Developmental Science, 5, 41-55.

Stuart, J., Ward, C., \& Adam, Z. (2010). Current issues in the development and acculturation of Muslim youth in New Zealand. ISSBD Bulletin, 58, 9-13.
Suarez-Orozco, C., \& Suarez-Orozco, M.M. (2001). Children of immigration. Harvard University Press, Cambridge, MA.

Wilmes, M., Schneider, J., \& Crul, M. (2011). Sind die Kinder türkischer Einwanderer in anderen Ländern klüger als in Deutschland? [Are children of Turkish immigrants in other countries more clever than in Germany?] In U. Neumann \& J. Schneider (Hrsg.), Schule mit Migrationshintergrund (pp. 30-46). Waxmann, Münster. 